\title{
Conservatory Students' Music Performance Anxiety and Educational Expectations: A Qualitative Study
}

\section{Hepsen Okan ${ }^{\star}$ Buse Usta $^{2}$ (D)}

'Assistant Professor, Ankara University State Conservatory (Voice Department), Turkey. Email:okanhepsen@gmail.com

${ }^{2}$ Psychological Counselor, Turkey.

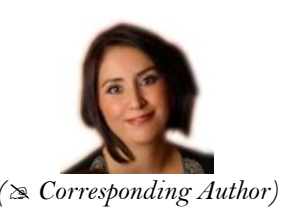

\begin{abstract}
Music performance anxiety (MPA) can seriously and negatively affect musicians' performance and quality of life-physically, mentally, and behaviorally. In the present study, factors related to the MPA of students receiving classical Western music education in the conservatory in a holistic framework were examined to ascertain the physical, mental, and behavioral symptoms; temporal processes; environmental factors; coping strategies; and educational expectations and desires related to this condition. In addition to investigating causative factors in such a framework, the content analysis method was used on data collected from semi-structured interviews with conservatory students. The results show that the main causative factors of MPA included a jury's negative evaluation, attitudes, and/or behaviors; their symptoms included trembling, muscle contraction, and distraction. The main coping strategy among participants was positive self-talk; remarkably, they had no theoretical knowledge of positive self-talk. Most significantly, considering that performance is integral to musical education training, students stated that the conservatory needs to integrate into the curriculum a course, counseling, and activities that address MPA.
\end{abstract}

Keywords: Music performance anxiety, Stress, Music education, Conservatory, Phenomenology, Educational expectations.

Citation | Hepsen Okan; Buse Usta (2021). Conservatory Students' Music Performance Anxiety and Educational Expectations: A Qualitative Study. Asian Journal of Education and Training, 7(4): 250-259.

History:

Received: 10 August 2021

Revised: 12 October 2021

Accepted: 8 November 2021

Published: 23 November 2021

Licensed: This work is licensed under a Creative Commons

Attribution 3.0 License (cc) Er

Publisher: Asian Online Journal Publishing Group
Acknowledgement: Both authors contributed to the conception and design of the study.

Funding: This study received no specific financial support.

Funding: This study received no specific financial support.
Competing Interests: The authors declare that they have no conflict of interests.

Transparency: The authors confirm that the manuscript is an honest, accurate, and transparent account of the study was reported; that no vital features of the study have been omitted; and that any discrepancies from the study as planned have been explained.

Ethical: This study follows all ethical practices during writing.

\section{Contents}

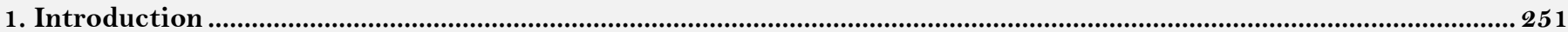

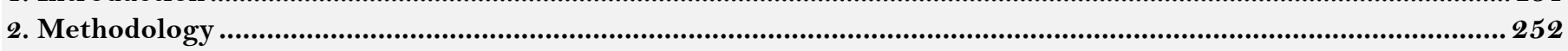

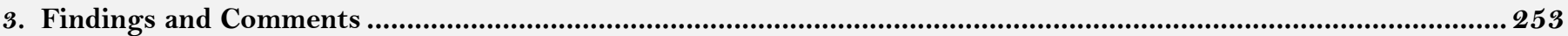

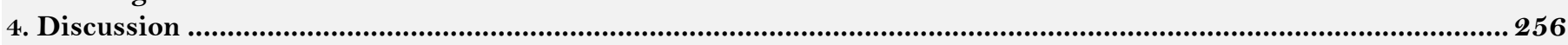

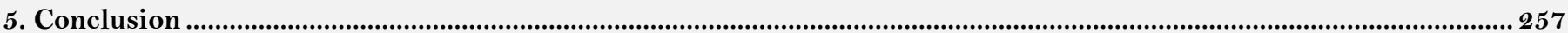

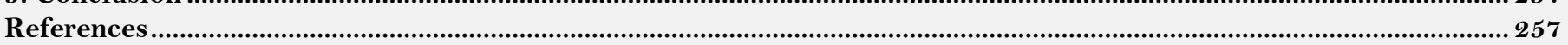




\section{Contribution of this paper to the literature}

This study fills an important gap due to the limited number of studies examining the factors that cause MPA in a wide framework in Western Classical Music students in Turkey. The key results of the study are that Students' MPA peaks during evaluated and juried performances, but takes the form of less "stage excitement" during regular concerts. Most significantly, results showed that students wanted to learn about MPA and coping with it through their curriculum - a course, psychological support, and more onstage experience. In addition, they wished to reschedule, and perhaps increase, evaluations of their skill and progress. The paper's findings provide an impetus for the reorganization of the curriculum for MPA in Conservatories at the undergraduate level.

\section{Introduction}

A plethora of studies on music performance anxiety (MPA) has shown that it is common to musicians of all ages in every genre, with many negative effects. However, as stated in the literature, MPA is mostly observed in musicians who perform Western classical music. Indeed, the Turkish national literature has published many experimental and qualitative studies about MPA (Can \& Akbal, 2021; Çiçek \& Güdek, 2020; Çırakoğlu, 2013; Coşkun-Şentürk \& Çırakoğlu, 2018; Guven, 2017; Tokinan, 2013; Topoğlu \& Karagulle, 2018; Topoğlu, 2014; Yondem, 2007). Although the literature cites MPA as a common problem, no curriculum or course addresses it in conservatories and institutions that provide undergraduate music education in Turkey. For student-musicians, anxiety about performing their best can be extremely high, particularly in performance-evaluative situations (Tang \& Ryan, 2020). In this context, this research reveals opinions on MPA by students who study Western classical music, their experiences of MPA, and their perceived educational expectations and requests on the subject.

According to Demirbatir (2015), "music students began to work from a very early age within an extremely demanding environment not only in physical but also in psychological terms. Their educational environment can be considered as a stressful place because of high competition, isolation, failure to achieve career goals, authoritarian teaching style, and intolerance against errors caused by stress or anxiety" (p. 2198). Musicians experience psychological pressure, anxiety disorders, and MPA peculiar to the conservatory environment where their training begins and in music schools throughout their lives (Buma, Bakker, \& Oudejans, 2015; Pecen, Collins, \& MacNamara, 2016; Pecen, Collins, \& MacNamara, 2018; Perkins, Reid, Araújo, Clark, \& Williamon, 2017).

As a specific condition, MPA may be experienced by all ages of both professional and amateur musicians, with negative impacts on performance (Biasutti \& Concina, 2014; Clark \& Williamon, 2011; Coşkun-Şentürk \& Çırakoğlu, 2018; Huang \& Song, 2021; Kaleńska-Rodzaj, 2020; Kenny \& Osborne, 2006; Kenny \& Ackermann, 2015; Kenny, Driscoll, \& Ackermann, 2014; Miller \& Chesky, 2004; Pecen et al., 2018; Perdomo-Guevara, 2014; Robinson \& Nigbur, 2018; Sieger, 2017; Skoogh \& Frisk, 2019; Yöndem, 2012). MPA is specifically defined as persistent distressing anxiety, actual deterioration in performance skills, deviation in performance from a normal physical and mental state, and physical, cognitive, and behavioral problems, despite the individual's education and preparation (Lehrer, 1987; Salmon, 1990). While the American Psychiatric Association (2013) defines MPA as social anxiety, Kenny (2011) states that it can be classified as an anxiety disorder affecting people of all ages. Others have reported its association and common aspects with social anxiety (Hook \& Valentiner, 2002; Kenny.. 2006). Apart from that, Kenny, Davis, and Oates (2004) found perfectionism and state and trait anxiety significant in MPA. Although many musicians experience MPA at some level, it can be so severe as to threaten careers and seriously affect the quality of life regardless of age, experience, environment, and performance type. In other words, MPA can be a multi-dimensional process encompassing a variety of cases, levels, and temporal processes.

As in the entire world, the literature shows that MPA is a common condition among musicians in Turkey. Also in line with the literature as a whole, Teztel and Aşkın (2007) found that students who perform Western classical music in Turkey were more inclined to MPA than jazz and traditional music students (Papageorgi, Creech, \& Welch, 2011; Ioulia Papageorgi, Hallam, \& Welch, 2007; Perdomo-Guevara, 2014). Moreover, studies on MPA using inventories, qualitative review, and psychoeducation programs have been conducted with Turkish musicians (Baydağ \& Alpagut, 2016; Cirakoğlu \& Şentürk, 2013; Cornett \& Urhan, 2021; Coşkun-Şentürk \& Çırakoğlu, 2018; Doğan \& İskender, 2015; Gürşen Otacıŏ̆lu, 2016; Saylam \& Girgin, 2019; Topoğlu \& Karagulle, 2018; Uluocak, 2016; Yöndem, 2012). These studies' results were compatible with the literature generally, which found greater MPA in female musicians and soloists (Casanova, Zarza, \& Orejudo, 2018; Kenny \& Osborne, 2006; Margaret S Osborne \& Franklin, 2002; Stephenson \& Quarrier, 2005).

After examining MPA with children, adolescents, and adults, Kenny and Osborne (2006) stated that the condition is not related to age, experience, or performance environment. However, he found that Barlow's anxiety model can help us understand performance anxiety overall and especially MPA. Barlow found anxiety to arise from biological (hereditary) vulnerability, psychological vulnerability based on early experiences, and vulnerability of certain situations and issues (Barlow, 2000). Many studies address psychological, physiological, and behavioral symptoms of MPA (Fernholz et al., 2019; Kenny. \& Ackermann, 2015; McGinnis \& Milling, 2005; Osório, Burin, Nirenberg, \& Barbar, 2017; Taborsky, 2007). Papageorgi. (2020) stated that sensitivity to audience presence and the rate of exposure to it significantly increased MPA. "Performance anxiety has a complex structure and is closely associated with social anxiety and exam anxiety"(Kenny et al., 2004; Papageorgi., 2020; Patston \& Osborne, 2016; Vaag, Bjørngaard, \& Bjerkeset, 2016). As mentioned in the studies above, the biological and psychological predisposition of a person to MPA has a complex structure, with MPA triggered by environmental factors.

Nagel reported that professional musicians are aware that a successful performance is not guaranteed by increased practice hours and also that MPA depends on personal characteristics, attitudes, and unconscious conflicts (Nagel, 1990).Ioulia Papageorgi et al. (2007) and Papageorgi. (2020) reported that MPA increases with the tendency to experience performance anxiety, with factors affecting performance quality, and with environmental performance factors. "Practice makes perfect" is a belief widely adopted in music performance, but practice alone does not always serve to cope with MPA.

Biasutti and Concina (2014) reported MPA higher among music students—constituting this study's volunteer participant. I. Papageorgi et al. (2011) conducted a study on MPA and different types of music, finding that higher 
levels of MPA were reported among Western classical music performers and soloists. Following this line, Teztel and Aşkın (2007) stated that students performing Western classical music had higher MPA. Similarly, Kenny... et al. (2014) reported in their study on MPA and psychological well-being that female musicians and young musicians had higher MPA. Cirakoğlu and Şentürk (2013) and Robson and Kenny (2017) stated that both music and nonmusic majors experienced MPA in ensemble rehearsals and concerts and that depression significantly triggered MPA levels. Dobos, Piko, and Kenny (2019) found a relationship between MPA, social phobia, and perfectionism. Topoğlu. (2014) found that $81.8 \%$ of performers experienced MPA before and during a performance, adversely affecting the performance of $60 \%$. As these studies demonstrate, MPA should be broadly understood and evaluated according to its unique features.

In Turkey, music education takes place in primary and secondary schools, in undergraduate, postgraduate, and doctoral studies, and Proficiency in Art programs. Performance training is conducted in conservatories, fine arts high schools, music education departments, and undergraduate faculties of fine arts (Orhan \& Tunca, 2014; Sahin \& Duman, 2008). Performance-oriented training is mainly offered in Western classical music and Turkish music conservatories under the umbrella of professional music education (Gök, 2018). In conservatory and music education programs, undergraduates try to cope with MPA through individual efforts and methods (Baydağ \& Alpagut, 2016; Hatfield, 2016; Yıldırım \& Simşek, 2006). However, related literature advises that the psychological aspect of music performance needs to be included in undergraduate music curricula, just as athletes whose profession is performance receive training in psychological skills (Cohen \& Bodner, 2019; Cornett \& Urhan, 2021 ; Gill, 2020; Hatfield, 2016; Hoffman \& Hanrahan, 2012; Osborne, Greene, \& Immel, 2014; Robson \& Kenny, 2017). In this regard, determining the needs and expectations of students, particularly in conservatories and music education institutions, is vital to professional competence. Given that MPA is associated with many causative factors, revealing the opinions of conservatory (Western classical music) students on MPA in the light of literature-specific themes will greatly contribute to music education and literature.

In Turkey, "no health promotion or injury prevention programs [are] presented at any of the tertiary institutions offering music as a major. Growing awareness of health issues is a fairly recent development among musicians and music teachers in Turkey" (Demirbatir, 2015). Despite studies' recognition of MPA as a common problem, no curriculum or course addressing it is offered in Turkish conservatories and institutions that provide undergraduate music education. To worsen matters, according to Kenny and Ackermann, treating performance anxiety is not easy, and reducing anxiety completely is quite difficult, so the best treatment is the prevention of MPA (Kenny \& Ackermann, 2007).

\subsection{The Current Study}

Therefore, using a holistic approach, this study explored general views of conservatory students of Western classical music on MPA-about self-reported anxiety, factors causing MPA, and their expectations and demands regarding MPA. In addition, factors related to MPA were determined in line with students' opinions about it—an important topic investigated for the first time in the national literature. The following research questions were used:

1) What are the opinions of conservatory music students on MPA?

2) What are their physical and mental experiences due to MPA?

3) What are their coping strategies and techniques?

4) What are the environmental factors that students experience because of MPA?

5) What are students' experiences regarding MPA and temporal processes?

6) What are their educational expectations and demands for eliminating MPA?

The research's overall aim was to reveal conservatory students' physical, cognitive, and behavioral symptoms, coping strategies and techniques, temporal processes, and their needs, demands, and expectations for MPA elimination by examining MPA-causative factors within a holistic framework.

\section{Methodology}

\subsection{Study Group and Data Collection}

Because individuals with experience of the studied phenomenon were required, this study used Patton (2002). From the Department of Performing Arts, the study group included voice/choir majors and from the Department of Music, instrument majors at Ankara University State Conservatory, 2019-2020 academic year. State conservatory students in preparatory, 1st, 2nd, 3rd and 4th grades $(\mathrm{N}=23 ; 15$ female and 8 male students $)$ were voluntarily included in the study. Snowball sampling method was used in the selection of the participants. Their performance fields included voice, choir, piano, violin, cello, and, flute.

We first obtained permission from the Ethics Committee and from the institution to conduct the study. A researcher and a musician conducted face-to-face and telephone interviews lasting 30-45 minutes, depending on students' availability, from April to June 2020.

\subsection{Research Model}

The phenomenological pattern focuses on phenomena about which we know but have no deep or detailed understanding. Thus, interpretive phenomenological analysis involves exploring and understanding participants' lived experience because phenomena may appear in different ways such as events, experiences, perceptions, tendencies, concepts, and situations in the world (Smith, 2004; Willig, 2008; Yıldırım \& Simşek, 2006). This study, which focused on conservatory students' experiences with MPA, has an interpretive phenomenological pattern aiming to identify conservatory students' experiences of and opinions about MPA. For a qualitative research method, phenomenology, acquiring knowledge about music education, a deep understanding of theory, as well as practice make important contributions (Bresler, 2010; Randles, 2012). 


\subsection{Data Collection}

Data for this research were collected with a semi-structured interview process, that is, by asking somewhat structured but flexible interview questions, with the majority of the interview consisting of problems to be clarified; collecting specific data from each participant; and including no pre-determined statement and question details (Merriam, 2018). A pilot interview was conducted before the study. Before the interviews, three field specialists evaluated the proposed questions; after necessary corrections were made based on their feedback, the researcher who worked as a psychological counselor held individual interviews with the 23 conservatory students.

\subsection{Data Analysis and Trustworthiness}

The researchers converted data obtained from the interview audio recordings to written text and coded them. Next, using the MAXQDA software program, the researchers analyzed the data using inductive content analysis: “... Data collected in the content analysis should be conceptualized in line with the study objectives, and themes should be determined in light of these concepts. The content analysis is generally based on the compilation of similar data within the scope of certain concepts and themes and the organization and interpretation of them so that the reader can understand" (Yıldırım \& Simşek, 2006). Therefore, considering the literature, researchers formed categories in line with the themes organized by coding. During data analysis, researchers discussed any statements on which they disagreed until they could a consensus. After checking the coding, categories, themes, and all other stages against the literature, researchers determined the extent to which results represent the analyzed dataset (Poggenpoel \& Myburgh, 2003). Before that, however, during the interview process, participants were asked to what extent their statements reflected their thoughts and feelings; they were then provided the opportunity to revise their statements, adding or deleting content. Despite being unable to guarantee an independent reality, the researchers attempted to ensure reliability by clarifying questions, obtaining participants' confirmations during interviews, supporting results with coding by an external expert, linking results with quotations from participants and the relevant literature, and evaluating the analysis itself (Daymon \& Holloway, 2003).

The reliability ratio between coders can be calculated by dividing the number of agreed-upon codes by the total number of agreed-upon and disagreed-upon codes. The reliability ratio between coders is not expected to be more than $70 \%$; preferably, it should be close to $80 \%$ or even more than $90 \%$ depending on the dataset's size (Arastaman, Fidan, \& Fidan, 2018; Fidan \& Öztürk, 2015; Miles \& Huberman, 1994). Our coders achieved compatibility of 82\%, and themes obtained from data analysis were supported with exact quotations.

\section{Findings and Comments}

The findings obtained in this study were collected under six categories, including the opinions of the participants about MPA; symptoms of MPA; coping strategies with MPA; temporal processes related to MPA; types of MPA; environmental factors causing MPA; and educational expectations to eliminate MPA. The results were presented with the statements of the participants in line with the data obtained from the participants.

In the first sub-problem of the research, the answer to the question "What are the opinions of the conservatory students regarding MPA" was sought. Findings regarding the data obtained from this question are given in Table 1 .

Table-1. Opinions of conservatory music students regarding MPA.

\begin{tabular}{l|l}
\hline Jury's negative evaluation (13) & Inadequate practice (5) \\
\hline Technical insufficiency (11) & Jury's appreciation (5) \\
\hline Perfectionism (8) & Competition and auditions (3) \\
\hline Personal stressors (8) & Lack of stage experience (3) \\
\hline Solo recital and exams (5) & Stage excitement (anxiety) (3) \\
\hline
\end{tabular}

First, we asked conservatory students their opinions regarding causative factors of MPA. Some students distinguished between MPA as fear of negative evaluations and MPA as excitement about performing in a concert or simply "stage excitement." In line with relevant literature, the majority of participants mentioned juries' negative performance evaluations in solo recitals, examinations, competitions, and auditions as causing MPA. When students have to prove themselves to a jury and experts, they describe MPA more negatively than in concerts, where they found MPA more positive and more motivating:

In my opinion, there is something called stage fright. The second is fear of the jury.

Music performance anxiety is something that happens a lot in exams. Even if there is a person I come across in the exam, even my teacher, this is something that makes one more nervous and panic.

It would be better if they evaluate and score us through the year rather than through the examination system. It would be more accurate for them to evaluate us during concerts and during lessons.

What I'm most excited about is the piano recital and exam. You have to prove yourself because it is a jury.

I think a lot. I have a lot of thoughts about whether the teachers will like it or not. I observe them a lot to see how they will react, especially my teacher. Because I wonder if I can control the sound and because of the teacher opening and closing his/her mouth, I get a lot of panics.

The second highest cause of MPA for participants was technical insufficiency. This finding is considered studyspecific because it is rarely encountered in the literature.

If there is a passage that I have difficulty playing when I go out to play, I think I will be disgraced.

While I am singing a piece, I can worry about singing it in the right position with the singing technique.

In Table I, the findings that depend on the jury factor are as follows: jury's negative evaluation, solo recitals and exams, jury's appreciation, and competition and auditions. The other causative factors mentioned-technical insufficiency, perfectionism, personal stressors, inadequate practice, and lack of stage experience-are largely consistent with the relevant literature. Stage excitement (anxiety) felt in concerts and similar events was stated more positively. However, all these factors cause physical, behavioral, and cognitive symptoms in students. 
In the second sub-problem of the research, the answer to the question "What are the physical and mental experiences of conservatory music students due to MPA?" was sought. Findings regarding the data obtained from this question are shown in Table 2.

Table-2. Symptoms of MPA in conservatory music students.

\begin{tabular}{l}
\hline Table-2. Symptoms of MPA in conservatory music students. \\
\hline Trembling and muscle contraction $(18)$ \\
\hline Palpitation (13) \\
\hline Fear $(9)$ \\
\hline Excessive stress $(8)$ \\
\hline Lack of sleep (7) \\
\hline Sweating (2) \\
\hline Panic (3) \\
\hline Nausea-gastric problems $(2)$ \\
\hline Dry mouths $(2)$ \\
\hline Frequent urination $(1)$ \\
\hline
\end{tabular}

Second, in the research, we asked participants about their physical and mental experiences with MPA.

Among physical, cognitive, and behavioral symptoms related to MPA, students most mentioned distraction; this coincides with difficulties in concentration and focus, which are frequently cited in the literature. Trembling and muscle contraction was the second most common finding:

I can't even think about the note I played. I look at it blankly, I think, we will talk to the teacher when the note comes out during breaks.

I can't think. I wish I thought so I wouldn't mix up the words. I need to focus on that moment. I lose my intellectual ability during the exam.

I often get locked whether there is a person in [front] of me or not. My body contracts. I suggest myself but then my hands are shaking, and this also affects my voice, and my voice gets hoarse.

The findings in Table II are also compatible with the literature in terms of the physical, cognitive, and behavioral aspects of MPA. Cognitive and behavioral symptoms include distraction, excessive stress, fear, panic, lack of sleep; physical symptoms include trembling, muscle contractions, palpitations, nausea, gastric problems, sweating, dry mouth, and frequent urination. In the face of these symptoms, students stated that they use various physical and cognitive coping strategies.

In the third sub-problem of the research, the answer to the question of "What are the coping strategies and techniques of conservatory music students for MPA?" was sought. Findings regarding the data obtained for this question are in Table 3.

Table-3. Coping strategies and techniques of conservatory music students for MPA.

\begin{tabular}{l}
\hline Positive self-talk (20) \\
\hline Self-motivation $(6)$ \\
\hline Changing posture during performance (5) \\
\hline Imagination (5) \\
\hline Playing with peers (3) \\
\hline Breath exercises (3) \\
\hline Medication (2) \\
\hline Meditation (2) \\
\hline Superstitious beliefs $(2)$ \\
\hline
\end{tabular}

Many studies address functional and dysfunctional coping strategies adopted by amateur and professional musicians for MPA. Related to the third problem, this study's participants revealed that they used physical and cognitive coping strategies commonly cited in the literature, but positive self-talk was the most used:

I encourage myself. I say to myself that I am divine. I say you are divine, I don't care about the people there, I simplify it, I say never mind, and so now I learned to control it a little. I say to myself, "There are things you can do well, show yourself." I am giving positive suggestions to myself, "Look, people like you and so make your best."

Don't care what the jury says. You're doing well. I say "Focus on your breathing."

I am motivating myself at that moment. Because you have to leave that passage and focus on other parts. You have to keep going.

A remarkable result of the study was positive self- talk (Table 3). Positive self-talk is a strategy frequently used in sports psychology, but athletes are psychologically trained to apply certain methods and techniques knowingly. With no theoretical knowledge of positive self-talk, nevertheless, participants in this study chose it from among their range of coping strategies. Results also revealed that they used additional physical and cognitive coping strategies commonly noted in the literature: self-motivation, changing posture during performance, breathing exercises, playing with peers, imagination, medication, meditation, and superstitious beliefs. Examination of MPA's symptoms and coping strategies indicates the importance of the context and the performance environment, especially since, as previously stated, many environmental factors can cause MPA.

In the fourth sub-problem of the research, the answer to the question "What are the environmental factors experienced by conservatory music students because of MPA?" was sought. Environmental factors related to MPA in the study are shown in Table 4.

Table-4. Environmental factors experienced by conservatory music students.

\begin{tabular}{l|l}
\hline Performance exam anticipation and fatigue (13) & Physical conditions of stage and acoustic performances (7) \\
\hline Attitudes and behaviors of the jury (9) & Verbal feedback (from jury) (3) \\
\hline Jury's appreciation (9) & Differences in instruments for pianists (1) \\
\hline
\end{tabular}


Fourth, we asked study participants about environmental factors, that is, physical and psychological environmental conditions related to MPA. Remarkably, most participants cited waiting for performance exams and fatigue as physical causes of MPA. The study also revealed that the second most cited environmental factors were the jury's appreciation and their attitudes and behaviors.

Besides waiting for performance exams, fatigue, and the jury's behaviors, including their feedback, physical conditions causing MPA also include the stage, the acoustics, and, for pianists, differences in instruments:

My excitement starts while I wait. I was worried while waiting for the long performances before me.

The people outside in the waiting room make me very nervous because they listen to your voice and they talk there, and you know it. I think the stage swallowed your voice.

Acoustics disturbs me, and if the environment is dry, especially when the air conditioners are working, my performance is affected.

Secondarily, psychological environmental conditions were related to MPA, as follow:

I am thinking about so many things. I mostly think about whether the lecturers will like it or not. I watch their reactions a lot, and I also often look at my lecturer. I do it to see whether I can control my voice, but then he/she opens and closes his/her mouth, and this also makes me nervous.

The gestures of the person (jury) opposite me mostly distract me. I feel quite comfortable if I am singing something very well, but I understand that I made a mistake when I see their gestures, and this makes me think even only at that moment and to deplore my mistakes and poor performance. The gestures and feedbacks of the people do not make me happy during the examination.

First, I think the stage absorbs the voice and leaves us numb there, and second, the stage and the people in the waiting room make me very nervous.

As shown in Table IV, the impact of physical and psychological environmental conditions related to MPA on the participants is a major factor. Environmental factors that cause MPA occur within a certain time frame for the participants. Findings regarding these temporal processes are discussed below.

In the fifth sub-problem, the answer to the question "What are the experiences of conservatory music students regarding the temporal processes related to MPA?” was sought. Findings based on the data obtained are shown in Table 5. Temporal processes related to MPA in the study are also shown in Table 6.

\begin{tabular}{l} 
Table-5. Experiences of conservatory students regarding MPA and temporal processes. \\
\hline One night before the performance $(11)$ \\
When taking place on the stage (6) \\
\hline Waiting for the performance $(4)$ \\
At the start of the performance $(2)$ \\
When traveling to the performance venue $(1)$ \\
\hline
\end{tabular}

In Table 5, the most frequently mentioned and the most severe MPA was observed on the night before to performance. In general, participants experienced anxiety at five different points during the performance process: a) while waiting for the performance to begin, b) at the start of the performance, c) when taking the stage, d) the night before the performance e) when traveling to the performance venue.

I feel comfortable 3-4 days before the performance; I only feel anxiety one night before the exam. I'm getting a little stressed out.

It begins one day before the exam. Even if I am completely ready for the piece, will I be able to do [it] or not? I say, "I have to sleep," but I am losing my sleep. I think I should go with the flow.

I feel it during my first steps to the stage, but it comes again when I see the lecturers' attitudes. I get nervous in my first steps to the stage, and I open up when singing, but it starts again when I see the lecturers.

Professional musicians give many performances throughout their lives, but not every musician experiences MPA to the same level. The literature states that some musicians experience anxiety before the performance, while others experience it during and after the performance. These findings are compatible with the literature, and they reflect MPA as it affects the general quality of participants' lives and performance quality. In this context, then, we know that students should have professional knowledge about MPA.

In the sixth problem of the research, the question is "What are the needs and expectations of conservatory music students to eliminate MPA?" Participants in the study stated that they most needed a course in the curriculum to manage MPA. Table VI shows the needs and expectations of the participants regarding MPA in their conservatory education.

\begin{tabular}{l} 
Table-6. Educational expectations and demands of conservatory music students to eliminate MPA. \\
\hline Course for MPA management in the curriculum $(9)$ \\
\hline Acquire physical and mental skills related to relaxation $(8)$ \\
\hline Arrangements for exam format $(5)$ \\
\hline More stage experiences expectation $(4)$ \\
\hline Psychologist's support, counseling $(4)$
\end{tabular}

Sixth and finally, we asked, "What do conservatory students need to alleviate and/or eliminate MPA?” Among other things, study participants said they most needed a course to help them learn to manage MPA. As shown in Table 6, among other things, study participants said they most needed a course to help them learn to manage MPA.

Participants want detailed and theoretical knowledge about coping with MPA, preferably through an MPA Management Course added to the curriculum. The second most frequently mentioned need is acquiring physical and mental relaxation skills, suggesting that students see relaxation as an effective method for reducing MPA.

You are on stage and people expect something from you. Especially at a young age, they exaggerate a small problem and turn it into a big one, and this occurs when combined with anxiety caused by a lack of musical self- 
confidence. If normal people experience this state in magnitude five, they experience it in magnitude twenty-five. Therefore, taking an education or an elective course on this subject will provide psychological relief.

A course would be beneficial. We are going to be artists, and if we want to be a real artist, we should control these issues. Something will always happen when we are on the stage, so we have to control this. If we learn it this way and practice it effectively, things would be easier on the stage.

I think everyone studying performing arts should have a class in their schedule called stage performance anxiety because we try to deal with something all the time. Sometimes you need help from somebody. For example, I used to have stage fright. I got over it two years ago, but I don't know how I did it. Maybe, if we had a lecturer talking on this issue during our first years, or if we had one course a week, or if counseling or something like psychological service was available, we would be more relaxed, and everyone would be a little healthier.

About physical and mental relaxation, a participant said,

My voice sounds great in rooms and courses, and the lack of adjustment affected my voice by thirty percent. I thought I should do something about it myself. I said that I should study this subject with practices such as meditation and breathing exercises. I thought it would be useful. I thought this question wasn't just about sound, it was something more personal. Because what we do is not the sound work, but the stage and excitement. I thought of checking all of these out. We do meditation or breathing exercises, yoga. We have a dance class and we do some yoga in it and it feels so good. But after all, it's a dance class.

The finding "Arrangement for Exam Format" expresses an expectation about organizing exams as workshops at certain time intervals, indicating that students want more frequent evaluation and evaluation of their developmental progress. Furthermore, at a conservatory, they expected more onstage experience, which would likely help them reduce MPA. Participants also mentioned support from a psychologist or counselor, which likely addresses a personal need for help with MPA, in addition to the resources mentioned above.

According to these findings, study participants seem to have acquired MPA coping skills and strategies through random and individual efforts. However, findings also revealed that students' developmental and performance needs were not being met by the curriculum; students strongly desire inclusion of a required course for overcoming anxiety.

\section{Discussion}

A broad range of studies on MPA in Turkey and worldwide have shown that even experienced professional musicians are subject to various levels of MPA because performances' content, environment, and context often stress musicians, even to the point of causing severe or debilitating MPA. Thus, this study specifically examined physical, mental, and behavioral manifestations of MPA among conservatory students (Western classical music), along with their coping strategies, factors causing their anxiety, and their needs for ameliorating the situation. Accordingly, study data were obtained through semi-structured interviews and then coded and content analyzed using MAXQDA, v. 2020.4, qualitative data analysis package program. One significant finding is that students regularly experience some MPA onstage, but their discomfort is exacerbated during an exam or a jury evaluation, as previous studies have found (Osborne \& Franklin, 2002; Osborne, Kenny, \& Holsomback, 2005; Yöndem, 2012). Causative factors in this study included perfectionism and inadequate preparation, thus following causative factors in the literature Fehm and Schmidt (2006); Yondem (2007); Osborne and Kenny (2008); Kenny et al. (2014); Sarıkaya (2018). Similar to Yondem (2007) and Teztel and Aşkın (2007), this study found that students had anxiety of being evaluated, the anxiety of being acclaimed, and stage anxiety. In other words, anxiety has both positive and negative effects on music performance, and it can contribute positively to performance to some degree (Alptekin, 2012; Castiglione, Rampullo, \& Cardullo, 2018). When it came to being evaluated and acclaimed, this study's participants perceived MPA particularly negatively. In contrast, they identified stage excitement among (anxiety) features as positive and motivating in less-pressured events such as concerts or workshops.

The most commonly stated cognitive and physical manifestations of MPA included, respectively, distraction and inability to concentrate, trembling and muscle contractions-similar to previous studies (Kenny et al., 2014; Kirchner, 2003). In Kirchner (2003), the pianist participants stated that physiological manifestations of performance anxiety increased their negative thoughts and feelings—as students also stated in this studystimulating the sympathetic nervous system.

In this study, participants used physical and cognitive coping strategies for MPA, but they had no field-specific, theoretical knowledge about them. Even so, students' breathing exercises, self-suggestion, and medication paralleled results by Osório et al. (2017) and Kenny et al. (2014). However, such efforts may vary depending on factors like individual predisposition and conditions (Biasutti \& Concina, 2014; Coşkun-Şentürk \& Çırakoğlu, 2018). Gannon (2015) suggested that because physiological symptoms directly affect other types of symptoms (cognitive and behavioral), physiological symptoms should be eliminated first in MPA treatment. Among this study's participants, the most commonly used coping strategy was positive self-talk for physical and cognitive manifestations of MPA. In this context, then, the students have not used the most effective strategies to address MPA.

The main environmental factors cited as causing MPA were the audience and the jury's acclamation, attitude, and behaviors. This result showed similarity to "Prevalence and Predictors of Music Performance Anxiety in Adolescent Learners: Individual and Environmental Factors" by Papageorgi (2020), suggesting that sensitivity to the audience's presence and the rate of exposure significantly increased MPA. In this context, educators might observe students' personal inclinations toward MPA through juried events such as pre-tests, exams, recitals, and so on and motivate students to discover and use coping strategies they find the most effective.

Because MPA can be thought of as a whole, with cognitive, somatic, and behavioral factors, effective use of psychological skills can contribute to the educational process. Hatfield (2016) stated that psychological skills training (e.g., goal setting, concentration, imagination, self-talk, arousal regulation) has been used successfully in sports for the last 50 years but is rarely used in music performance. In this regard, the study's most remarkable result was that students stated they need a course, counseling, and activities on MPA integrated into the curriculum. However, examination of Turkish music education programs did reveal courses on concert and stage 
psychology, but they are not common and are mostly in master and doctoral curricula. According to Yildırım (2020), performing before professional musicians and academicians is not easy for music students, and adequate technical, musical, and mental preparation is highly important. Investigation of performance-based sports education-training programs revealed courses on sports psychology, which emphasizes that psychological as well as physical skills should be developed. In music education that focuses on performance, coping with stress, anxiety, concentration, motivation, and effective management of pre- and post-performance processes can be defined as important skills. Therefore, including courses and activities in the conservatory curriculum at the undergraduate level, from which students can gain the psychological skills to manage MPA will provide significant benefits.

A final significant result was the students' expressed need to extend the exam process during educationtraining and to enrich their onstage experiences through concerts and other performances. In other words, extending the exam and evaluation process with lecturers in the jury in the education-training environment and supporting it with exams without a jury would reduce students' MPA.

\section{Conclusion}

This study's results showed that MPA is quite common among students, but they do not have detailed, literature-based knowledge about it. Nor have they intentionally and consciously used proven coping strategies, like athletes are trained to do. Because performance is integral to musical education training, including courses and activities on coping with MPA should be part of the licensing and education curriculum in all conservatories and institutions providing musical education degrees. The activities repeatedly mentioned here could contribute significantly to occupational competencies.

Although this study achieved important results, its limitations can be summarized as follows. The obtained data was based mainly on self-reports by volunteer participants attending a single conservatory in Turkey. Thus, the subject should be investigated through varied contexts and samples from Turkish conservatories and music departments. Although many researchers have investigated MPA, it is still regarded as a complex and significant problem among musicians. In this regard, to focus on MPA and psychobiology within the context of its holistic, physical, and psychological effects and on the need for preventive MPA education, about which the literature currently offers little information.

\section{References}

Alptekin, G. A. (2012). Anxiety of music performance. Trakya University Journal of Social Sciences, 14(1), 137-147.

American Psychiatric Association. (2013). Diagnostic and statistical manual of mental disorders (5th ed.). Arlington, VA: American Psychiatric Association Publishing.

Arastaman, G., Fidan, İ. Ö., \& Fidan, T. (2018). Validity and reliability in qualitative research: A theoretical analysis. YYU Journal of Education Faculty, $15(1), 37-75$.

Barlow, D. H. (2000). Unraveling the mysteries of anxiety and its disorders from the perspective of emotion theory. American Psychologist, 55(11), 1247-1263. Available at: https://doi.org/10.1037/0003-066x.55.11.1247.

Baydağ, C., \& Alpagut, U. (2016). Comparison of department of music education and conservatory students in terms of stage/performance anxiety pilot study. Journal of International Social Research, 9(44), 857-864.

Biasutti, M., \& Concina, E. (2014). The role of coping strategy and experience in predicting music performance anxiety. Musicae Scientiae, $18(2), 189-202$. Available at: https://doi.org/10.1177/1029864914523282.

Bresler, L. (2010). Ethnography, phenomenology and action research in music education. Visions of Research in Music Education, 6(3), 4-16.

Buma, L. A., Bakker, F. C., \& Oudejans, R. R. (2015). Exploring the thoughts and focus of attention of elite musicians under pressure. Psychology of Music, 43(4), 459-472. Available at: https://doi.org/10.1177/0305735613517285.

Can, Ü. A., \& Akbal, B. (2021). An analysis of graduate studies in Turkey about musical performance anxiety. Turkish Studies, 16(1), 85-101. Available at: https://dx.doi.org/10.7827/TurkishStudies.46795.

Casanova, O., Zarza, F. J., \& Orejudo, S. (2018). Differences in performance anxiety levels among advanced conservatory students in Spain, according to type of instrument and academic year of enrolment. Music Education Research, 20(3), 377-389. Available at: https://doi.org/10.1080/14613808.2018.1433145.

Castiglione, C., Rampullo, A., \& Cardullo, S. (2018). Self representations and music performance anxiety: A study with professional and amateur musicians. Europe's Journal of Psychology, 14(4), 792-805. Available at: https://doi.org/10.5964/ejop.v 14i4.1554.

Çiçek, V., \& Güdek, B. (2020). Adaptation of the music performance anxiety İnventory to Turkish: A validity and reliability study. Journal of Academic Social Science Studies, 81, 153-163. Available at: http://dx.doi.org/10.29228/JASSS.45980.

Çırakoğlu, C. (2013). The enemy on the stage: A review of performance anxiety in musicians. Turkish Psychology Articles, 16(32), 95-106.

Cirakoğlu, O. C., \& Şentürk, G. C. (2013). Development of a performance anxiety scale for music students. Medical Problems of Performing Artists, 28(4), 199-206. Available at: https://doi.org/10.2 1091/mppa.2013.4040.

Clark, T., \& Williamon, A. (2011). Evaluation of a mental skills training program for musicians. Journal of Applied Sport Psychology, 23(3), 342-359. Available at: https://doi.org/10.1080/10413200.2011.574676.

Cohen, S., \& Bodner, E. (2019). Music performance skills: A two-pronged approach-facilitating optimal music performance and reducing music performance anxiety. Psychology of Music, 47(4), 52 1-538. Available at: https://doi.org/10.1177/0305735618765349

Cornett, V., \& Urhan, G. (2021). Performance anxiety experiences and coping techniques of Turkish music students and their teachers. International Journal of Music Education, 0255761421 10059. Available at: https://doi.org/10.1177/02557614211005907.

Coşkun-Şentürk, G., \& Çırakoğlu, O. C. (2018). How guilt/shame proneness and coping styles are related to music performance anxiety and stress symptoms by gender. Psychology of Music, 46(5), 682-698. Available at: https://doi.org/10.1177/0305735617721338.

Daymon, C., \& Holloway, I. (2003). Qualitative research methods in public relations and marketing communications. London: Routledge.

Demirbatir, R. E. (2015). Relationships between psychological well-being, happiness, and educational satisfaction in a group of university music students. Educational Research and Reviews, 1O(15), 2198-2206. Available at: https://doi.org/10.5897/err2015.2375.

Dobos, B., Piko, B. F., \& Kenny, D. T. (2019). Music performance anxiety and its relationship with social phobia and dimensions of perfectionism. Research Studies in Music Education, 41(3), 310-326. Available at: https://doi.org/10.1177/1321103x18804295.

Doğan, U., \& İskender, M. (2015). The functionality of a psycho-education programme for reducing music performance anxiety among students at high school of fine arts. Kastamonu Education Journal, 23(1), 311-328.

Fehm, L., \& Schmidt, K. (2006). Performance anxiety in gifted adolescent musicians. Journal of Anxiety Disorders, 20(1), 98-109. Available at: https://doi.org/10.1016/j.janxdis.2004.11.011.

Fernholz, I., Mumm, J., Plag, J., Noeres, K., Rotter, G., Willich, S., . . Schmidt, A. (2019). Performance anxiety in profe ssional musicians: A systematic review on prevalence, risk factors and clinical treatment effects. Psychological Medicine, 49(14), 2287-2306. Available at: https://doi.org/10.1017/s0033291719001910.

Fidan, T., \& Öztürk, İ. (2015). Perspectives and expectations of union member and non-union member teachers on teacher unions. Journal of Educational Sciences Research, 5(2), 191-220. Available at: https://doi.org/10.12973/jesr.2015.52.10.

Gannon, P. (2015). Don't call it stage fright! New ideas about treating music performance anxiety. International Musician, 113(12), 16-16. 
Gill, A. (2020). Enhancing music performance self-efficacy through psychological skills training Doctoral Thesis. Faculty of Fine Arts and Music Melbourne Conservatorium of Music University of Melbourne. Retrieved from: https://minervaaccess.unimelb.edu.au/bitstream/handle/11343/235510/5ad73b60-9fd6-e911-94ab0050568d7800_Gill_199021941.pdf? sequence=1\&isAllowed=y.

Gök, M. (2018). An analysis of professional music education in the context of newly opened universities, faculties and departments of music in Turkey. Journal of Higher Education and Science, 8(2), 280-297. Available at: https://doi.org/10.5961/jhes.2018.271.

Gürşen Otacioğlu, S. (2016). Performance anxiety and academic success level examination of students in Turkey. International Journal of Educational Research Review, 1(2), 25-33. Available at: https://doi.org/10.24331/ijere.309964.

Guven, E. (2017). Levels of music performance anxiety and test anxiety of Turkish prospective music teachers in piano exams. International Journal of Music Education, 35(2), 154-164. Available at: https://doi.org/10.1177/0255761415620530.

Hatfield, J. L. (2016). Performing at the top of one's musical game. Frontiers in Psychology, 7, 1356. Available at: https://doi.org/10.3389/fpsyg.2016.01356.

Hoffman, S. L., \& Hanrahan, S. J. (2012). Mental skills for musicians: Managing music performance anxiety and enhancing performance. Sport, Exercise, and Performance Psychology, 1(1), 17-28. Available at: https://doi.org/10.1037/a0025409.

Hook, J. N., \& Valentiner, D. P. (2002). Are specific and generalized social phobias qualitatively distinct? Clinical Psychology: Science and Practice, 9(4), 379-395. Available at: https://doi.org/10.1093/clipsy/9.4.379.

Huang, W.-L., \& Song, B. (2021). How do college musicians self-manage musical performance anxiety: Strategies through time periods and types of performance. International Journal of Music Education, 39(2), 95-118. Available at: https://doi.org/10.1177/0255761421990800.

Kaleńska-Rodzaj, J. K. (2020). Music performance anxiety and pre-performance emotions in the light of psychology of emotion and emotion regulation. Psychology of Music, 1-17. Available at: https://doi.org/10.1177/0305735620961154.

Kenny, D. T., Davis, P., \& Oates, J. (2004). Music performance anxiety and occupational stress amongst opera chorus artists and their relationship with state and trait anxiety and perfectionism. Journal of Anxiety Disorders, 18(6), 757-777. Available at: https://doi.org/10.1016/j.janxdis.2003.09.004.

Kenny, D. T., \& Osborne, M. S. (2006). Music performance anxiety: New insights from young musicians. Advances in Cognitive Psychology, 2(2-3), 103-112. Available at: https://doi.org/10.2478/v10053-008-0049-5.

Kenny, D., \& Ackermann, B. (2015). Performance-related musculoskeletal pain, depression and music performance anxiety in professional orchestral musicians: A population study. Psychology of Music, 43(1), 43-60. Available at: https://doi.org/10.1177/0305735613493953

Kenny, D. T. (2006). Music performance anxiety: Origins, phenomenology, assessment, and treatment. Journal of Musicological Research, 31 , $51-64$.

Kenny, D. T. (2011). The psychology of music performance anxiety. Oxford, UK: Oxford University Press.

Kenny, D. T., \& Ackermann, B. (2007). Anxiety in public performance, stress and health issues for musicians. Oxford handbook of music psychology. Oxford, UK: Oxford University Press.

Kenny, D., Driscoll, T., \& Ackermann, B. (2014). Psychological well-being in professional orchestral musicians in Australia: A descriptive population study. Psychology of Music, 42(2), 210-232. Available at: https://doi.org/10.1 177/0305735612463950.

Kirchner, J. M. (2003). A qualitative inquiry into musical performance anxiety. Medical Problems of Performing Artists, 18(2), 78-82. Available at: https://doi.org/10.21091/mppa.2003.2015.

Lehrer, P. M. (1987). A review of the approaches to the management of tension and stage fright in music performance. Journal of Research in Music Education, 35(3), 143-153.

McGinnis, A. M., \& Milling, L. S. (2005). Psychological treatment of musical performance anxiety: Current status and future directions. Psychotherapy: Theory, Research, Practice, Training, 42(3), 357-373.

Merriam, S. (2018). Qualitative research: A guide to design and implementation (3rt ed., pp. 1-292). Ankara: Nobel Academic Publishing.

Miles, M., B., \& Huberman, A. M. (1994). Qualitative data analysis: An expanded sourcebook (2nd ed.). Thousand Oaks: CA: SAGE.

Miller, S. R., \& Chesky, K. (2004). The multidimensional anxiety theory: an assessment of and relationships between intensity and direction of cognitive anxiety, somatic anxiety, and self-confidence over multiple performance requirements among college music majors. Medical Problems of Performing Artists, 19(1), 12-22. Available at: https://doi.org/10.2 1091/mppa.2004.1003

Nagel, J. J. (1990). Performance anxiety and the performing musician: A fear of failure or a fear of success. Medical Problems of Performing Artists, 5(1), 37-40.

Orhan, Y. S.., \& Tunca, B. (2014). The list of graduate theses in the field of chamber music in Turkey. Folklor/Edebiyat, 20(80), 207-219.

Osborne, M. S., \& Franklin, J. (2002). Cognitive processes in music performance anxiety. Australian Journal of Psychology, $54(2)$ ), 86-93.

Osborne, M. S., Greene, D. J., \& Immel, D. T. (2014). Managing performance anxiety and improving mental skills in conservatoire students through performance psychology training: A pilot study. Psychology of Well-Being, 4(1), 1-17. Available at: https://doi.org/10.1186/s13612-014-0018-3.

Osborne, M. S., \& Kenny, D. T. (2008). The role of sensitizing experiences in music performance anxiety in adolescent musicians. Psychology of Music, 36(4), 447-462. Available at: https://doi.org/10.1177/0305735607086051.

Osborne, M. S., Kenny, D. T., \& Holsomback, R. (2005). Assessment of music performance anxiety in late childhood: A validation study of the music performance anxiety inventory for adolescents. International Journal of Stress Management, 12(4), 312-330. Available at: https://doi.org/10.1037/1072-5245.12.4.312.

Osório, F., Burin, A., Nirenberg, I., \& Barbar, A. (2017). Music performance anxiety: Perceived causes and coping strategies. European Psychiatry, 41(S1), S110-S110. Available at: https://doi.org/10.1016/j.eurpsy.2017.01.1883.

Papageorgi, I., Creech, A., \& Welch, G. (2011). Perceived performance anxiety in advanced musicians specializing in different musical genres. Psychology of Music, 4(1), 18-41. Available at: https://doi.org/10.1177/0305735611408995.

Papageorgi, I., Hallam, S., \& Welch, G. F. (2007). A conceptual framework for understanding musical performance anxiety. Research Studies in Music Education, 28(1), 83-107. Available at: https://doi.org/10.1177/1321103x070280010207.

Papageorgi, I. (2020). Prevalence and predictors of music performance anxiety in adolescent learners: Contributions of individual, taskrelated and environmental factors. Musicae Scientaie, 1-22. Available at: https://doi.org/10.1177/1029864920923128.

Patston, T., \& Osborne, M. S. (2016). The developmental features of music performance anxiety and perfectionism in school age music students. Performance Enhancement \& Health, 4(1-2), 42-49. Available at: https://doi.org/10.1016/j.peh.2015.09.003.

Patton, M. Q. (2002). Qualitative research and evaluation methods. Thousand Oaks: CA: SAGE.

Pecen, E., Collins, D., \& MacNamara, Á. (2016). Music of the night: performance practitioner considerations for enhancement work in music. Sport, Exercise, and Performance Psychology, 5(4), 377-395. Available at: https://doi.org/10.1037/spy0000067.

Pecen, E., Collins, D. J., \& MacNamara, Á. (2018). "It's your problem. Deal with it.” Performers' experiences of psychological challenges in music. Frontiers in Psychology, 8, 2374.

Perdomo-Guevara, E. (2014). Is music performance anxiety just an individual problem? Exploring the impact of musical environments on performers' approaches to performance and emotions. Psychomusicology: Music, Mind, and Brain, 24(1), 66-74. Available at: https://doi.org/10.1037/pmuo000028.

Perkins, R., Reid, H., Araújo, L. S., Clark, T., \& Williamon, A. (2017). Perceived enablers and barriers to optimal health among music students: A qualitative study in the music conservatoire setting. Frontiers in Psychology, 8, 1-15. Available at: https://doi.org/10.3389/fpsyg.2017.00968.

Poggenpoel, M., \& Myburgh, C. (2003). The researcher as research instrument in educational research: A possible threat to trustworthiness?(A: research_instrument). Education, 124(2), 418-423.

Randles, C. (2012). Phenomenology: A review of the literature. Update: Applications of Research in Music Education, 30(2), 11-21. Available at: https://doi.org/10.1177/8755123312436988.

Robinson, G., \& Nigbur, D. (2018). Experiences of musical performance anxiety in final-year undergraduate music students: an interpretative phenomenological analysis. Social Psychological Review, 2O(1), 18-32. Available at: https://repository.canterbury.ac.uk/item/88774. 
Robson, K. E., \& Kenny, D. T. (2017). Music performance anxiety in ensemble rehearsals and concerts: A comparison of music and nonmusic major undergraduate musicians. Psychology of Music, 45(6), 868-885. Available at: https://doi.org/10.1177/0305735617693472.

Sahin, M., \& Duman, R. (2008). Music education in the reconstruction period of the republic. CTTAD, 7(16-17), 259-272. Available at: https://dergipark.org.tr/en/pub/cttad/issue/25239/266856.

Salmon, P. G. (1990). A psychological perspective on musical performance anxiety: A review of the literature. Medical Problems of Performing Artists, 5(1), 2-11.

Sarıkaya, M. (2018). Prediction of musical performance anxiety according to music student teachers' beliefs on perfectionism and self-efficacy. Doctoral Thesis, Necmettin Erbakan University Institute of Education Sciences.

Saylam, B., \& Girgin, D. (2019). Music performance anxiety: Symptoms, causes, coping strategies. Journal of Limitless Education and Research, 4(2), 189-199. Available at: https://doi.org/10.29250/sead.569751.

Sieger, C. (2017). Music performance anxiety in instrumental music students: A multiple case study of teacher perspectives. Contributions to Music Education, 42, 35-52. Available at: https://www.jstor.org/stable/26367435.

Skoogh, F., \& Frisk, H. (2019). Performance values-an artistic research perspective on music performance anxiety in classical music. Journal for Research in Arts and Sports Education, 3(1), 1-15. Available at: https://doi.org/10.23865/jased.v3.1506.

Smith, J. A. (2004). Reflecting on the development of interpretative phenomenological analysis and its contribution to qualitative research in psychology. Qualitative Research in Psychology, 1(1), 39-54. Available at: https://doi.org/10.1 191/1478088704qp0040a.

Stephenson, H., \& Quarrier, N. F. (2005). Anxiety sensitivity and performance anxiety in college music students. Medical Problems of Performing Artists, 20(3), 119-125. Available at: https://doi.org/10.21091/mppa.2005.3024.

Taborsky, C. (2007). Musical performance anxiety: A review of literature. Update: Applications of Research in Music Education, 26(1), 15-25. Available at: https://doi.org/10.1177/87551233070260010103.

Tang, Y., \& Ryan, L. (2020). Music performance anxiety: Can expressive writing intervention help? Frontiers in Psychology, 11 , 1334. Available at: https://doi.org/10.3389/fpsyg.2020.01334.

Teztel, G., \& Aşkın, C. (2007). The prevalence of performance anxiety among Turkish musicians and effective coping methods. İtü Dergisi/b Sosyal Bilimler, $4(2), 3-10$.

Tokinan, B. O. (2013). The adaptation study of the Kenny music performance anxiety inventory into Turkish. AHI Evran University Journal of Kirsehir Education Faculty, 1(4), 53-65.

Topoğlu, O., \& Karagulle, D. (2018). General health status, music performance anxiety, and coping methods of musicians working in Turkish state symphony orchestras: A cross-sectional study. Medical Problems of Performing Artists, 33(2), 118-123. Available at: https://doi.org/10.21091/mppa.2018.2019-118-123.

Topoğlu, O. (2014). Musical performance anxiety: Relations between personal features and state anxiety levels of pre-service music teachers. International Online Journal of Educational Sciences, 6, 337-348. Available at: https://doi.org/10.15345/iojes.2014.02.008.

Uluocak, S. (2016). Stress sources of conservatory students. International Online Journal of Educational Sciences, 8(1), 216-228. Available at: https://doi.org/10.15345/iojes.2016.01.017.

Vaag, J., Bjørngaard, J. H., \& Bjerkeset, O. (2016). Symptoms of anxiety and depression among Norwegian musicians compared to the general workforce. Psychology of Music, 44(2), 234-248.

Willig, C. (2008). Introducing qualitative research in psychology (2nd ed.). Berkshire, UK: McGraw-Hill Professional Publishing.

Yıldırım, A., \& Simşek, H. (2006). Qualitative research methods in the social sciences. Ankara: Seçkin Publications.

Yıldırım, A. C. (2020). Performance anxiety and an analysis on the effects of associated stress problems experienced by pianists. Unpublished Doctoral Thesis. Ankara: Hacettepe University Institute of Fine Arts.

Yondem, Z. D. (2007). Performance anxiety, dysfunctional attitudes and gender in university music students. Social Behavior and Personality: An International Journal, 35(10), 1415-1426.

Yöndem, Z. D. (2012). Physical, behavioral and cognitive characteristics of perceived performance anxiety in music students: A qualitative study. Education Sciences, 37(166), 181-194. 